\title{
Support workers' attitudes to mental illness: implications for reducing stigma
}

\section{AIMS AND METHOD}

We conducted an anonymous survey of support workers to examine attitudes to people with different types of mental illness. Scores were based on a previously demonstrated stigmatisation score.

\section{RESULTS}

A total of 133 questionnaires were returned, representing $27 \%$ of all possible recipients. Fewer than $20 \%$ of respondents considered people with schizophrenia to be dangerous, although nearly half thought that they would never fully recover. More stigmatising responses were demonstrated to alcohol and drug addiction than to other disorders.

\author{
CLINICAL IMPLICATIONS \\ Support workers who spend large \\ amounts of time with people with \\ mental illness, in particular \\ schizophrenia, have a low \\ perception of their dangerousness. \\ This may have implications for \\ planning further measures to \\ reduce stigmatisation.
}

Stigmatisation of people with mental illness is an age-old issue that has been highlighted by the Royal College of Psychiatrists' campaign, 'Changing Minds' (http:// www.rcpsych.ac.uk/campaigns/cminds). In Scotland, the 'See Me' anti-stigma campaign has also addressed the discrimination that can be experienced (http:// www.seemescotland.org.uk). The stigmatisation of patients by health workers has been investigated, but much of the evidence is anecdotal.

This study examined the attitudes of mental health support workers attached to housing and voluntary agencies in Edinburgh towards mental illness. The population survey carried out by the Royal College of Psychiatrists' Campaign Management Committee in 1998 concluded that negative opinions contribute to the problems associated with mental disorder (Crisp et al, 2000). The present study used the same questionnaire, adapted for anonymous use rather than face-to-face interviews.

\section{Method}

The study was carried out in Edinburgh from November 2000 to June 2001. Twenty agencies providing supported accommodation for people with mental illness were identified through InTouch Edinburgh, a computerised community information database at the Royal Edinburgh Hospital. These included voluntary, charity and social work-funded organisations (permission was obtained from Edinburgh Social Work to contact the latter). Agencies providing support primarily for rehabilitation from drugs and alcohol, or for offenders were excluded, as workers would experience a different range of mental health issues. The agencies were contacted by telephone by one of the investigators and asked to take part. All accepted but one agency was subsequently excluded since it provided only for young people. Another identified two other addresses which were also contacted. The project received ethical approval from the Lothian Research Ethics Committee and management approval from the Lothian Primary Care NHS Trust Research and Development Committee.

Permission was granted by the Royal College of Psychiatrists to administer the questionnaire used by Crisp et al (2000), which examined attitudes of the British adult population to people with mental illness. Although the original survey was conducted in person, the investigators decided it would not be appropriate to do so in this survey. The investigators frequently liaised with support workers who might not feel comfortable in giving their views candidly in a face-to-face interview. Furthermore, in the current climate of anti-stigma drives, some may have been reluctant to respond to such a survey.

One investigator visited each agency, leaving a supply of questionnaires with a nominated person who distributed them. The same investigator visited again a few weeks later to collect the responses. A further visit was provided if requested.

Some of the larger organisations requested extra questionnaires so that they could distribute them to as many workers as possible. The sample was therefore approximated as a proportion of the estimated total number of workers.

The questionnaire concerned the seven disorders which had been studied in the College survey (severe depression, panic attacks, schizophrenia, dementia, eating disorders, alcohol addiction and drug addiction; Crisp et al, 2000). The questions pertained to dangerousness, unpredictability, being hard to talk to, being to blame for the condition, the likelihood of improvement with treatment, feeling different to others, the ability to pull oneself together and the prospect of eventual recovery. The wording was changed minimally to enable self-reporting.

A small number of questions were added to provide background information, including age, gender, time spent working with people with mental illness, average working hours and personal knowledge of mental illness (in relation to themselves, or contact with friends or family).

For each disorder, support workers indicated their degree of agreement with a statement on a 5-point 
7

original papers
Likert scale. These statements are listed as 'opinions' in Table 1. As in the College survey (Crisp et al, 2000), respondents were considered to have a 'negative' opinion if they chose either of the two responses on the 'negative' side of the mid-point of this scale. The proportions giving stigmatising responses were then calculated for all questions, and for each disorder (with 95\% confidence intervals).

A continuous measure of stigmatising attitudes was also calculated for each disorder. This was done by adding up the score for each item ( $1=$ least stigmatising, $5=$ most stigmatising) and summing it over all items for that disorder. The association between each score was then calculated using Pearson correlation coefficients.

The total of all scores was then calculated for each support worker and was taken as an overall measurement of stigmatising attitudes ('total stigma score'). To investigate whether this was associated with gender or personal knowledge of mental illness, we compared total scores between groups using a $t$-test. The relationship to number of years' experience and hours worked per week was also assessed, using correlation coefficients.

\section{Results}

A total of 133 questionnaires were returned and most were completed. At the time of the study, it was estimated that there were slightly fewer than 500 people working with all the agencies included. Many worked part time and may not have been offered a questionnaire, so it was not possible to calculate a response rate. The sample therefore represented approximately $27 \%$ of all possible support workers.

Of the sample, $87(65.4 \%)$ were women and 43 $(32.3 \%)$ were men ( 2 non-respondents); 114 (85.7\%) were in the 21- to 50-year age range, with $56(42.1 \%)$ in the 31 - to 40 -year age range. Only 2 were younger than 20 years and 15 older than 50 years. Fifty-five respondents $(41.4 \%)$ had spent fewer than 5 years working with people with mental illness, $42(31.6 \%)$ had spent between 6 and 10 years and 20 (15.0\%) between 11 and 15 years. A further 14 (10.5\%) had more than 15 years' experience. A total of 114 (85.8\%) were spending between 21 and 40 hours per week working with people with mental illness and only $18(13.5 \%)$ were spending 20 hours or fewer; 115 (86.5\%) had experience of mental illness, either personally or in relation to a friend or family member. The opinions of mental health workers with respect to the seven different types of mental illness are summarised in Table 1.

Alcohol and drug addiction produced more negative responses than other disorders and less than $20 \%$ of respondents considered people with schizophrenia as dangerous.

Few respondents considered that people were to blame for their problems or that they could pull themselves together. Alcohol and drug addiction scored most highly on this latter point, although more than $90 \%$ of respondents thought that those with alcohol and drug addiction would benefit from treatment.

People with dementia and schizophrenia were considered to have the worst long-term prognosis.

All stigma scales for each individual disorder were weakly correlated, with no single correlation coefficient less than 0.2 , and all were statistically significant at $P<0.05$.

In terms of the 'total stigma score', no significant differences were shown between men and women, or between those with and without a personal knowledge of mental illness. Similarly, no relationship was found between total stigma score and years of experience or time spent working with people with mental illness (hours per week)

\section{Discussion}

Although the role of support workers differs from that of other workers in mental health, they spend a considerable

Table 1. Support workers expressing a negative opinion of seven disorders, $\%(95 \% \mathrm{Cl})$

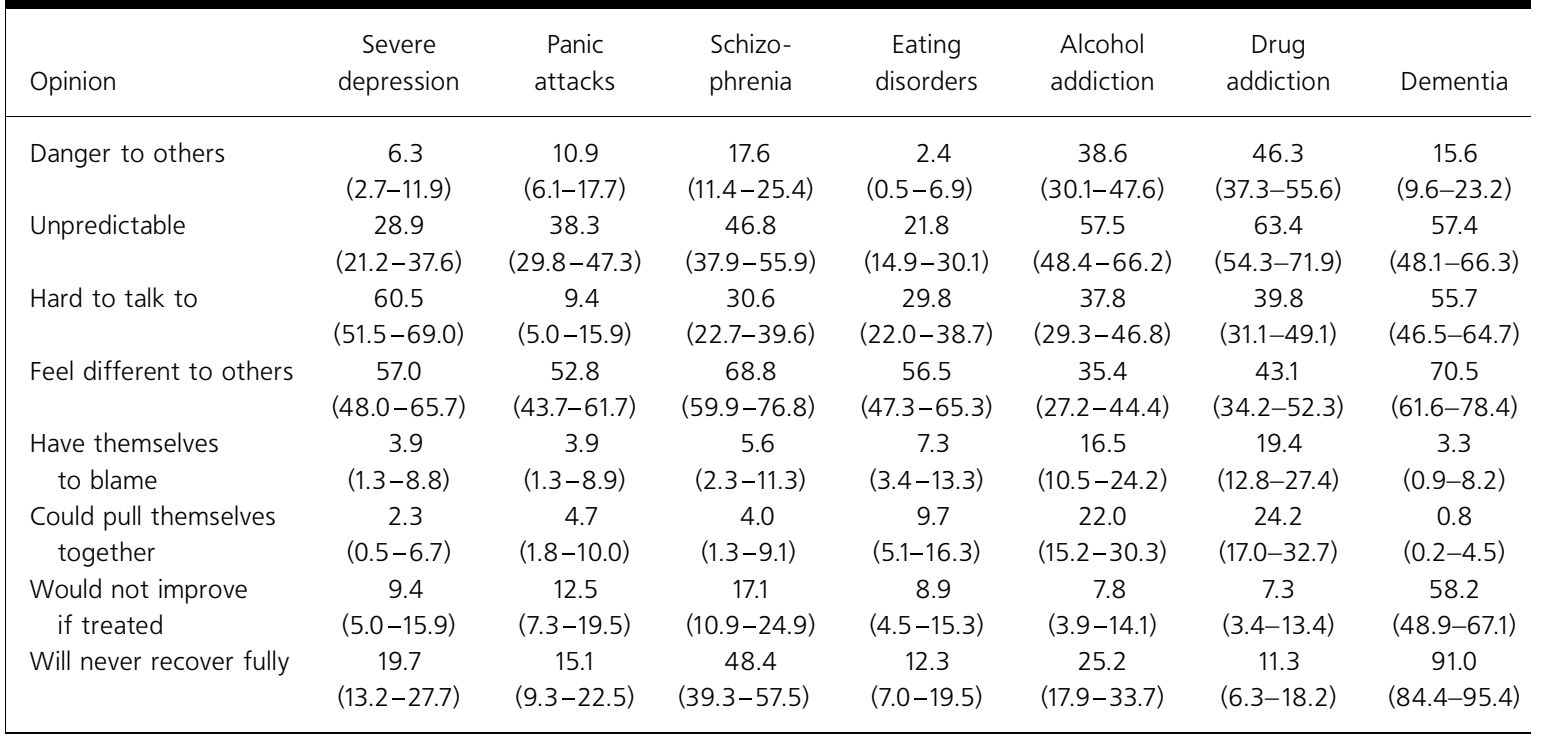


amount of time with people with severe and enduring mental illness. This client group is also at increased risk of other psychiatric disorders, in particular drug and alcohol dependence (Regier et al, 1990).

A similar study of medical students and doctors by Mukherjee et al (2002) found that more than half considered people with schizophrenia to be dangerous. Lawrie et al (1996) showed that general practitioners also have some negative attitudes towards those with schizophrenia. Dickerson et al (2002), in their article about out-patients with schizophrenia, commented that $20 \%$ of patients considered mental health caregivers to be an actual source of stigma. However, in general, there is some evidence that increased contact with mental illness may lead to less stigmatising attitudes among health professionals (Gray, 2002).

Crisp et al (2000) found that nearly three quarters of the general population (71.3\%) viewed people with schizophrenia as dangerous. Walsh et al (2002), in their review of violence and schizophrenia, confirmed the small absolute risk of violence in people with schizophrenia, a risk that is increased by comorbid substance misuse. Our survey showed a strikingly different result than that of Crisp et al, with fewer than $20 \%$ of respondents considering people with schizophrenia to be dangerous. Nearly half of the respondents considered them to be unpredictable, but this did not seem to automatically equate to being dangerous.

It is important to clarify the meaning of 'negative' or stigmatising responses. Although these were viewed as the negative response to a statement, they might constitute reasonable and informed opinion (for instance, that people with dementia will not recover fully). An illinformed positive opinion could ultimately lead to more discrimination. Smith (2002) referred to this as 'normalisation', emphasising that although differences cannot always be ignored, they can be accepted.

Few respondents considered that people were to blame for their problems, although this tended to be slightly higher for alcohol and drug addiction. The response rate in this survey was low, so results should be viewed with caution. However, this contrasts with Crisp et al's findings that one-third of the general public considered people with eating disorders, and more than half of those with alcohol and drug addiction, had themselves to blame. Support workers tended to be optimistic about the outcome for all disorders except dementia and schizophrenia, and did not expect people to 'pull themselves together'. This study showed a similar view regarding eventual recovery to that of the general public (Crisp et al, 2000), contrasting with the findings of Mukherjee et al (2002), which found that nearly fourfifths of doctors and medical students thought that people with schizophrenia could recover.

Given that opinions regarding treatment and recovery were similar to those held by the general public (Crisp et al, 2000) it is all the more interesting that the opinions regarding dangerousness were so different. Many support workers (86.5\%) had personal knowledge of mental illness and may have held these opinions before taking up work. However, it is also possible that spending time with people with mental illness is a powerful tool for changing attitudes. A study of college students by Corrigan et al (2001) suggested that contact with mental illness influences fear and social distance, and hence stigma. Huxley (1993) reported that contact with people who had had positive experiences of treatment was a key factor for reducing stigma.

However, it is also important to note that support workers do not always find it easy to talk to people with mental illness. Lack of acknowledgement of these difficulties could lead to feelings of personal inadequacy, perhaps resulting in avoidance.

Given that support workers spend a lot of time with people with schizophrenia, their low perception of dangerousness is interesting, and has implications in planning further measures to reduce stigmatisation. More investigation as to why this opinion is held and whether it is shared by other healthcare workers would be useful.

\section{Declaration of interest}

None.

\section{Acknowledgements}

We thank all the support workers who participated in this study.

\section{References}

CORRIGAN, P.W., GREEN, A., LUNDIN, $R$., et al (2001) Familiarity with and social distance from people who have serious mental illness. Psychiatric Services, 52, 953-958.

CRISP, A. H., GELDER, M. G., RIX, S., et al (2000) Stigmatisation of people with mental illnesses. British Journal of

Psychiatry, 177, 4-7.

DICKERSON, F. B., SOMMERVILLE, J., ORIGONI, A. E., et al (2002) Experiences of stigma among outpatients with schizophrenia. Schizophrenia Bulletin, 28, 143-155.

GRAY, A. J. (2002) Stigma in psychiatry. Journal of the Royal Society of Medicine, 95, 72-76.

HUXLEY, P. (1993) Location and stigma: a survey of community attitudes to mental illness: enlightenment and stigma. Journal of Mental Health UK, 2, $73-80$.

LAWRIE, S. M., PARSONS, C., PATRICK, J., et al (1996) A controlled trial of general practitioners' attitudes to patients with schizophrenia. Health Bulletin, 54, 201-203.

MUKHERJEE, R., FIALHO, A., WIJETUNGE, A., et al (2002) The stigmatisation of psychiatric illness: the attitudes of medical students and doctors in a London teaching hospital. Psychiatric Bulletin, 26, 178-181.

REGIER, D. A., FARMER, M. E., RAE, D. S., et al (1990) Comorbidity of mental disorders with alcohol and other drug abuse. Results from the Epidemiologic Catchment Area (ECA) Study. JAMA, 264, 2511-2518.

SMITH, M. (2002) Stigma. Advances in Psychiatric Treatment, 8, 317-323.

WALSH, E., BUCHANAN, A. \& FAHY,T. (2002) Violence and schizophrenia: examining the evidence. British Journal of Psychiatry, 180, 490-495.

*RebeccaTipper Consultant Psychiatrist, Borders Community Addictions Team, Galavale Lodge, Tweed Road, GalashielsTD1 1PF, e-mail: rebecca.tipper@borders.scot.nhs.uk, Deborah Mountain Consultant Psychiatrist, Royal Edinburgh Hospital, Stuart Lorimer Specialist Registrar in Liaison Psychiatry, Paterson Centre, London, Andrew McIntosh Senior Lecturer in Psychiatry, Royal Edinburgh Hospital original papers 